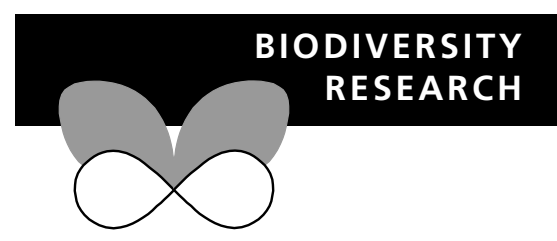

\title{
Can more $K$-selected species be better invaders? A case study of fruit flies in La Réunion
}

\author{
Pierre-François Duyck ${ }^{1 \star}$, Patrice David ${ }^{2}$ and Serge Quilici ${ }^{1}$
}

${ }^{1}$ UMR $53 \ll$ Peuplements Végétaux et Bio-agresseurs en Milieu Tropical $\gg$ CIRAD Pôle de Protection des Plantes (3P), 7 chemin de l'IRAT, 97410 St Pierre, La Réunion, France, ${ }^{2} U M R$ 5175, CNRS Centre d'Ecologie Fonctionnelle et Evolutive (CEFE), 1919 route de Mende, 34293 Montpellier Cedex, France

${ }^{*}$ Correspondence: Pierre-François Duyck, CIRAD 3P, 7, chemin de l'IRAT, 97410, St Pierre, La Réunion Island, France. Tel.: +262 2624992 31; Fax: +262 2624992 93; E-mail: duyck@cirad.fr

\begin{abstract}
Invasive species are often said to be $r$-selected. However, invaders must sometimes compete with related resident species. In this case invaders should present combinations of life-history traits that give them higher competitive ability than residents, even at the expense of lower colonization ability. We test this prediction by comparing life-history traits among four fruit fly species, one endemic and three successive invaders, in La Réunion Island. Recent invaders tend to produce fewer, but larger, juveniles, delay the onset but increase the duration of reproduction, survive longer, and senesce more slowly than earlier ones. These traits are associated with higher ranks in a competitive hierarchy established in a previous study. However, the endemic species, now nearly extinct in the island, is inferior to the other three with respect to both competition and colonization traits, violating the trade-off assumption. Our results overall suggest that the key traits for invasion in this system were those that favoured competition rather than colonization.
\end{abstract}

\section{Keywords}

Biological invasions, competitive displacement, life-history traits, $r-K$ trade-off, Tephritidae.

\section{INTRODUCTION}

Biological invasions are now considered one of the most important components of human-induced recent changes in the biosphere (Vitousek et al., 1996), and have dramatic impacts on both species distributions and global biodiversity (Lodge, 1993; Mack et al., 2000; Mooney \& Cleland, 2001). Thus, the identification of biological traits typical of potential invaders (Crawley, 1986; Gray, 1986; Mack, 1996; Kolar \& Lodge, 2001) and of features of invasible habitats (Lonsdale, 1999; Levine, 2000; Stachowicz et al., 2002; France \& Duffy, 2006; Richardson \& Pysek, 2006) has become an important challenge. Despite an increasing number of studies, it has been notoriously difficult to obtain robust generalizations, both because of the heterogeneity of taxa and ecosystems affected by invasion, and because of the predominant effect of variation in propagule pressure among case studies (Lonsdale, 1999; Kolar \& Lodge, 2001). A pervasive historical paradigm, although with quite ambiguous empirical support (see, e.g. Mack, 1996; Kolar \& Lodge, 2001), is the assumption that invasive species should be good colonists (Elton, 1958; Lodge, 1993; Williamson, 1996). Invasive species are defined on a biogeographical basis, as those that have recently been introduced and have established viable populations far from their original distribution areas (Williamson, 1996). In contrast, colonists have been historically defined by a set of biological traits including short generation times, short juvenile phase, high reproductive effort, production of many small, mobile offspring, and in some cases vegetative reproduction (Pianka, 1970). There has been much debate on the reality and exact nature of the 'colonist's syndrome' (MacArthur, 1962; Pianka, 1970; Grime, 1977; Stearns, 1992; Mueller, 1997; Reznick et al., 2002). Because the intrinsic growth rate is positively affected by such traits, they were termed ' $r$-selected traits' by Pianka (1970) and said to be advantageous in non-competitive environments such as early successional or otherwise unstable habitats (MacArthur, 1962). This theory is based on the assumption of a trade-off among traits so that competitive ability and $r$ cannot be maximized at the same time (MacArthur, 1962; Tilman, 1994; Kneitel \& Chase, 2004). Without questioning this principle, modern theory of lifehistory evolution has complexified this view, showing that a low sensitivity of early-life stages to competition, not necessarily the absence of competition, was the key condition for the evolution of the so-called ' $r$-traits' (Charlesworth, 1994; Mueller, 1997; Reznick et al., 2002). With this limitation in mind, the historical conception that invaders should be good colonists still must rely on two assumptions: (1) invaded habitats are often unsaturated or otherwise resemble the habitats that favour $r$-traits in native ranges, and (2) invasion is limited by the ability to rapidly spread and grow in numbers in such habitats. Both assumptions have received some empirical support, although not completely 
conclusive. Indeed, disturbed habitats seem more prone to invasions (Lozon \& MacIsaac, 1997; see, however, Bruno et al., 2004), and some comparisons between invaders and non-invasive related taxa highlight the role of traits typical of the so-called $r$-strategy (see Rejmanek, 1996 and references below). The best-known example is found in invasive conifers, in which several large-scale comparisons have revealed higher relative growth rate, smaller seed mass, shorter juvenile phase, and more frequent seed production in comparison to non-invasive species (Rejmanek \& Richardson, 1996; Grotkopp et al., 2002; Richardson \& Rejmanek, 2004). Similarly, invasive populations of Spartina alterniflora show earlier and larger reproductive effort, higher investment into vegetative reproduction, and lower selfincompatibility than their congeners from the native range in common garden experiments (Davis, 2005). Note, however, that component traits, rather than the intrinsic rate of increase itself, have been used in such studies.

Apart from the need for more data, a more basic criticism of the $r$-strategy hypothesis is that different contexts are expected to favour different types of invaders, and no single combination of traits can be successful everywhere (Holdgate, 1986; Lodge, 1993; Mack et al., 2000; Radford \& Cousens, 2000; Facon et al., 2004; Richardson \& Pysek, 2006). Invasion depends on an interaction between a species' traits and characteristics of the recipient ecosystem (Byers, 2002; Thuiller et al., 2006; see also the 'niche opportunity' concept in Shea \& Chesson, 2002), especially the resident community (Shea \& Chesson, 2002). A high intrinsic rate of increase by itself cannot impede invasion; however, if $r$-traits trade-off with traits important for the interaction with resident species, the relationship between invasive ability and $r$ could be negative instead of positive. For example, the $r$-selected traits in the oyster Crassostrea ariakensis do not make it a good invader because they come with a low investment in defence and high susceptibility to predation by blue crabs (Bishop \& Peterson, 2006).

Competition is an important component of the biotic environment of invasive species (Stachowicz \& Tilman, 2005). Of course, examples of invaders with traits typical of colonists are often associated with either disturbed habitats (case of woody plants, Rejmanek, 1996) or previously empty habitats (mudflats invaded by S. alterniflora in the US Pacific coast; Davis, 2005). However, not all invasions happen in such contexts (Byers, 2002; Daehler, 2003; Evans, 2004). In contexts where competition occurs and is an important constraint on the demography of invasive species, one expects, based on trade-off theory (Kneitel \& Chase, 2004), a negative relationship between $r$ and invasive success. Such a context has recently been identified in a group of four species of polyphagous fruit flies (tephritids) now inhabiting the island of La Réunion (Duyck et al., 2004a).

The family Tephritidae is well known for multiple invasions that pose important economic problems in fruit or vegetable crops in tropical and subtropical areas worldwide (Duyck et al., 2004a). Historical records are available because of the economic importance of these species, and they are easy to rear under laboratory conditions. Four species of ecologically very similar tephritids now inhabit La Réunion, including an endemic species Ceratitis catoirii Guérin-Mèneville, and three others that have successively invaded: Ceratitis capitata (Wiedemann) in 1939, Ceratitis rosa Karsch in 1955, and Bactrocera zonata (Saunders) in 1991. Each newly arrived species has partially excluded and/or displaced each other, and has become largely dominant over previous ones, at least in the lowlands $(<100 \mathrm{~m}$ a.s.l.), where the four species now coexist. An exception to this pattern is that $C$. rosa continues to be dominant in the highlands because the climate there is unsuitable for the other species (Duyck et al., 2006b). Duyck et al. (2006a), studying larval exploitative competition in fruits and interference between adult females for access to laying sites, concluded that competitive interactions were hierarchically organized, with recently arrived species systematically dominant on previous ones. In the same study, natural densities and coinfection rates in field-collected fruits were such that interspecific competition must occur in the field as it did in the laboratory.

This system is a good opportunity to test our hypothesis of a negative relationship between invasivity and $r$-traits, not only because competition has been a major component of invasions (Duyck et al., 2006a), but also because the species are similar enough, phylogenetically and ecologically, to provide meaningful comparisons of life-history traits and document potential trade-offs. We here use experiments in a common laboratory environment to establish the life tables of all four species (including both the intrinsic rate of increase and its component traits) and to test whether successive invaders are characterized by decreasing $r$ (or component traits), as predicted by our hypothesis. Our approach does not contrast invaders vs. non-invasive related species as done in previous studies of the relationship between traits and invasiveness; instead we compare invaders to their competitors (endemic and introduced) because our previous studies have shown that competition was a strong limit to invasion in this system (Duyck et al., 2004a). In such a context, what matters is the relative values of traits of the invader and its competitors rather than with external non-invasive species not involved in competition in the invaded area (Daehler, 2003; Vila \& Weiner, 2004).

\section{METHODS}

\section{Source material and rearing conditions for laboratory studies}

We measured life-history traits under laboratory conditions. We used laboratory strains of C. catoirii, C. capitata, C. rosa, and B. zonata, initiated from fruit samples collected in La Réunion, and subsequently reared on artificial diets optimized for each studied species [composition in Duyck \& Quilici (2002) and Duyck et al. (2004b)], for 30, 3, 51, and 6 generations, respectively. The populations were initiated with 50-100 individuals (C. catoirii) or 500-1000 individuals (other species) and later all maintained at several thousands of individuals per generation. Laboratory rearings were conducted at constant temperature $\left(25 \pm 1^{\circ} \mathrm{C}\right)$ and photoperiod (L12:D12) supplemented by natural light to maintain twilight conditions (necessary for mating). The temperature of $25^{\circ} \mathrm{C}$ was previously shown to be the most favourable for the four studied species (Duyck \& Quilici, 2002; Duyck et al., 2004b). 


\section{Adult life-history patterns}

Thirty newly emerged male-female pairs $(<2 \mathrm{~h})$ of each of all four species were each confined (1 pair per cage) in separate transparent plastic cages $(1 \mathrm{~L})$ aerated via meshed openings, in environmental chambers $\left(25 \pm 1{ }^{\circ} \mathrm{C}, 80 \pm 10 \% \mathrm{RH}, 4000\right.$ lux, L12:D12) (Strader, Pellouailles les Vignes, France). Flies had free access to a diet of sugar and enzymatic yeast hydrolysate (ICN Biomedical, Aurora, IL, USA), and a wet sponge was placed in a container as a water source. An orange table tennis ball (diameter $4 \mathrm{~cm})$, cut in half, and pierced with 24 evenly spaced holes $(418 \pm 90 \mu \mathrm{m})$, containing a piece of mango fruit (Mangifera indica L.) and inserted in a plastic base of suitable diameter, was used as a substrate for egg laying. Each morning, new egg cups were placed in all 120 cages to record daily fecundity. On the following day, the number of eggs was counted and each egg cup was replaced to maintain the females in constant conditions, dead males were replaced by new ones from the same cohort. The procedure was repeated until the last female died.

\section{Calculation and analysis of demographic parameters}

Daily adult survival and fecundity were combined with previously published data on developmental times and survival rates of immature stages (egg, larvae, and pupae) in the same fly strains at $25^{\circ} \mathrm{C}$ [Duyck \& Quilici (2002) for Ceratitis spp. and Duyck et al. (2004b) for B. zonata] to compute demographic parameters following standard methods (Carey, 1982; Ebert, 1999). Immature age-specific survivorship rates were interpolated as in Carey (1982). Confidence intervals for demographic parameters were estimated as the 2.5 and 97.5 percentiles of a bootstrap distribution resampled 1000 times (Efron \& Tibshirani, 1993; Caswell, 2001).

Daily fecundity curves were fitted by a log linear model with a Poisson error using GLIM software (Crawley, 1993). Fecundity was fitted as a seventh-order polynomial of age (log number of eggs $\left.=b_{0}+b_{1} x+b_{2} x^{2} \ldots+b_{7} x^{7}\right)$, within each species separately. We chose polynomial functions because they are flexible and provide smooth fitted curves while they impose no constraint on the form of the curve. We dropped the higher-order terms $(>7)$ because including further terms did not yield a significant increase in goodness of fit in any species. In some species, the term $x^{7}$ was non-significant but we nevertheless included it in order to treat all species the same way. We tested for significant differences among species in timing and magnitude of fecundity using the change in deviance between two models: one in which all coefficients are free to vary among species, and one with a common set of coefficients for all species ( $F$-test in analysis of deviance, Crawley, 1993). This allowed us to establish that species had significantly different overall fecundity patterns, i.e. polynomial fits do uncover significant differences among species. However, differences in polynomial coefficients have no simple interpretation, so the polynomial equations were used to extract several more informative quantities of interest. All polynomial curves showed a major peak followed by a progressive decrease in fecundity. We characterized these curves using the age at the major fecundity peak, its height, and the age interval during which fecundity exceeded half the peak value. Patterns of senescence in survival were analysed by fitting the Weibull mortality model (hazard function $h(t)=\lambda \alpha t^{\alpha-1}$ ) (Carey, 2001) using the software GLIM (Crawley, 1993). This formulation includes, as a special case $(\alpha=1)$, the basic exponential model. The senescence parameter $(\alpha)$ exceeds unity when mortality increases with age. Its significance was assessed by a likelihood-ratio test that compared the Weibull model with the exponential model (i.e. with the constraint $\alpha=1)$. To help interpretation, we also provide the mean life expectancy $\left(\mu=\lambda^{(1-\alpha)}\right)$ and the time interval after which estimated mortality rates are doubled $\left(d=2^{1 /(1-\alpha)}\right)$.

\section{Egg size and pupal mass}

Lengths of 50 randomly chosen eggs, collected from the stock colony $(N>1000)$, were measured for each species within $2 \mathrm{~h}$ of oviposition with the graduated graticule of a binocular microscope $(\times 32)$. Pupal masses were determined by individually weighing 160 young pupae ( $<4 \mathrm{~h}$ old) from one cohort of larvae of each species with a precision balance $\left(10^{-4} \mathrm{~g}\right)$. Differences in pupal mass and egg length among species were analysed by analysis of variance, after square-root transformation to ensure normality, and post hoc comparisons of means were performed using the Tukey HSD test (5\% level of significance).

\section{RESULTS}

Data regarding immature development and survival have been obtained from earlier studies on the same strains [Duyck \& Quilici (2002) for the three Ceratitis species and Duyck et al. (2004b) for B. zonata]. Pre-imaginal developmental times were significantly different among all species (ANOvA $F_{3,44}=1799.5$, $P<0.0001$, Table 1). However, the probability to survive to adulthood was much lower in $C$. catoirii than in the three invading species (anOva $F_{3,44}=528.4, P<0.0001$, Table 1 ). The four species had significantly different age-fecundity curves $\left(F_{24,4670}=64.3\right.$, $P<0.0001$ by model simplification; all pairs of species are significantly different at $P<0.0001$, Fig. 1). Knowing that our polynomials capture significant differences among species, and that all of them had a major fecundity peak early in reproductive life, we could use polynomial equations to extract the height, time, and duration of the fecundity peak. The three Ceratitis species began to oviposit 5-10 days after emergence, while B. zonata began oviposition 20 days after emergence but of the four, oviposited over a longer duration (Fig. 1 and Table 1). Ceratitis capitata and C. rosa showed similar egg-laying patterns, but the fecundity peak was higher and of shorter duration for C. capitata (Table 1). Temporal variation in fecundity of $C$. catoirii was similar to the two other Ceratitis spp. but with a very low maximum. Female survival curves decreased in a similar fashion for the four species until $c$. 40 days after emergence, after which, survivorship appeared to be higher in B. zonata (Fig. 1). The last females died after 82, 80, 95, and 126 days, respectively, for C. catoirii, C. capitata, C. rosa, and B. zonata. Weibull survival parameters were very similar for the three Ceratitis species. These three species senesce faster than 


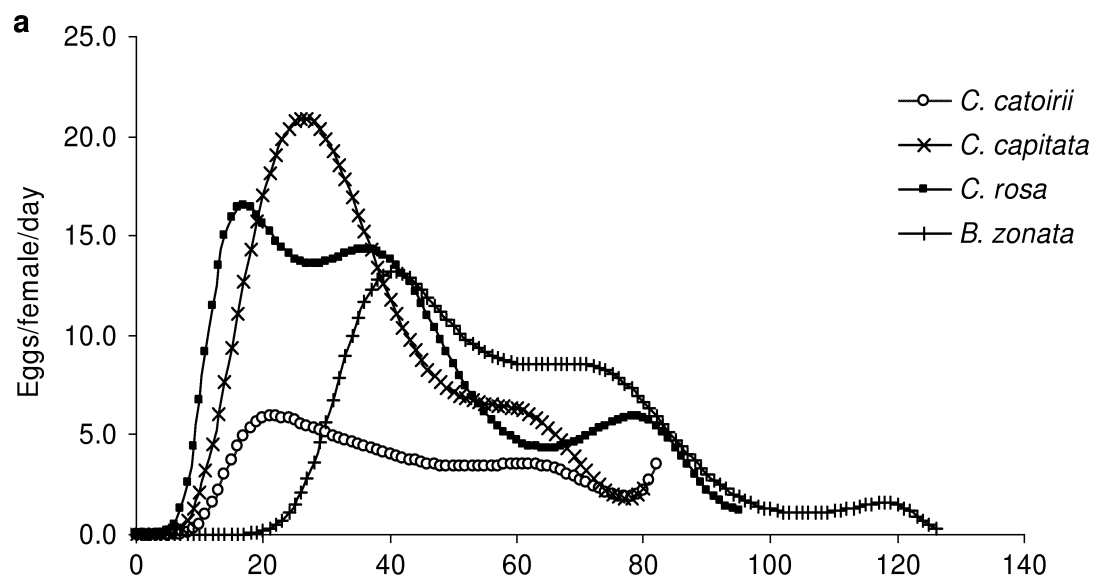

b

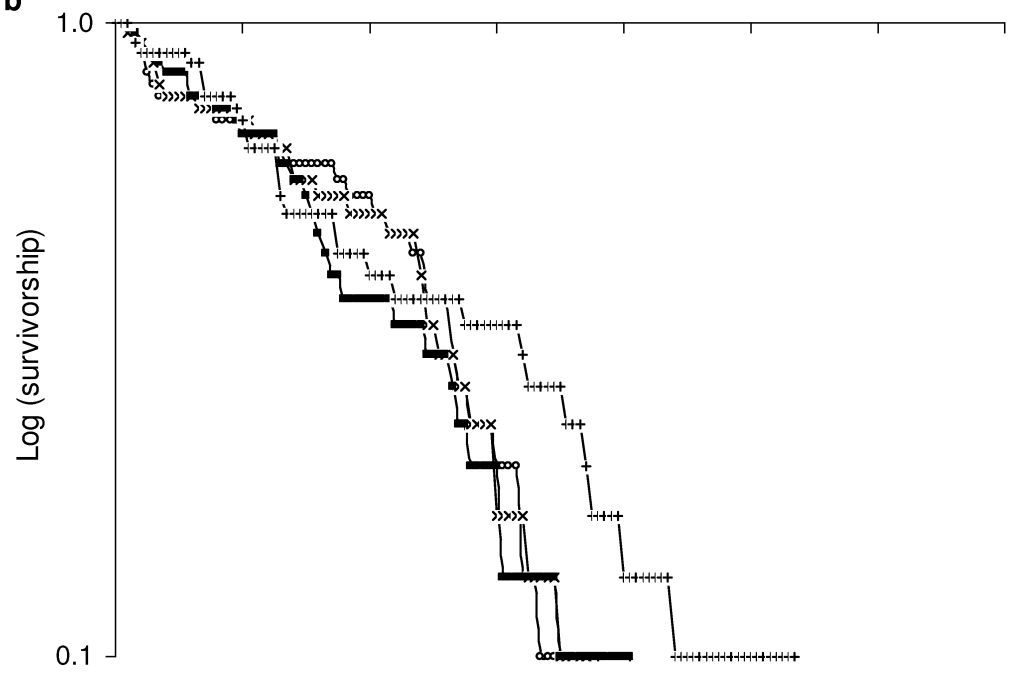

Adult age (days)

Figure 1 Fecundity and survival patterns in the four species. (a) Number of eggs laid per female per day. Fitted polynomial curves are given. In order to avoid extrapolation, each curve is stopped at the maximum age reached by experimental individuals.

(b) Female survivorship of Ceratitis catoirii, C. capitata, C. rosa and Bactrocera zonata.

Table 1 Life tables of Ceratitis catoirii, Ceratitis capitata, Ceratitis rosa, and Bactrocera zonata. The $P$-value for the Weibull model is the significance of the senescence parameter ( $\mathrm{H} 0: \alpha=1)$ tested by likelihood ratio. The doubling time of mortality is the age at which the death rate is twice its initial value. Cross at max/2 is defined as the two dates when the fecundity curve crosses the value of half maximum fecundity. Data regarding immature development and survival have been obtained from earlier studies on the same strains [Duyck \& Quilici (2002) for the three Ceratitis species and Duyck et al. (2004b) for B. zonata ${ }^{*}$ Means in the same line with the same superscript letter are not significantly different at the $5 \%$ level (Tukey HSD).

\begin{tabular}{|c|c|c|c|c|}
\hline Parameters & C. catoirii & C. capitata & C. rosa & B. zonata \\
\hline Date of invasion & Resident & 1939 & 1955 & 1991 \\
\hline Probability to survive from egg to adult* & $0.30^{c}$ & $0.73^{\mathrm{ab}}$ & $0.75^{\mathrm{a}}$ & $0.70^{\mathrm{b}}$ \\
\hline Mean age at emergence $(d)^{*}$ & $21.7^{\mathrm{b}}$ & $18.4^{\mathrm{c}}$ & $23.6^{\mathrm{a}}$ & $17.1^{\mathrm{d}}$ \\
\hline \multicolumn{5}{|l|}{ Fecundity parameters: } \\
\hline Maximum fecundity (eggs/d) & 5.9 & 20.9 & 16.6 & 13.2 \\
\hline Date of the maximum fecundity $(d)$ & 21.7 & 26.5 & 16.8 & 40.5 \\
\hline Cross at $\max / 2(d)$ & {$[13.9,50.5]$} & {$[15.7,41.9]$} & {$[10.6,50.5]$} & {$[30.9,80.2]$} \\
\hline \multicolumn{5}{|l|}{ Parameters of the Weibull model: } \\
\hline$\lambda$ & 0.006 & 0.004 & 0.005 & 0.008 \\
\hline$\alpha$ & 1.366 & 1.485 & 1.422 & 1.265 \\
\hline$\mu$ & 41.5 & 42.6 & 40.0 & 47.6 \\
\hline Doubling time of mortality $(d)$ & 6.6 & 4.2 & 5.2 & 13.7 \\
\hline Test: $P$-value & 0.02 & 0.06 & 0.03 & 0.12 \\
\hline
\end{tabular}


Figure 2 Expected stable age distribution of Ceratitis catoirii, Ceratitis capitata, Ceratitis rosa and Bactrocera zonata.

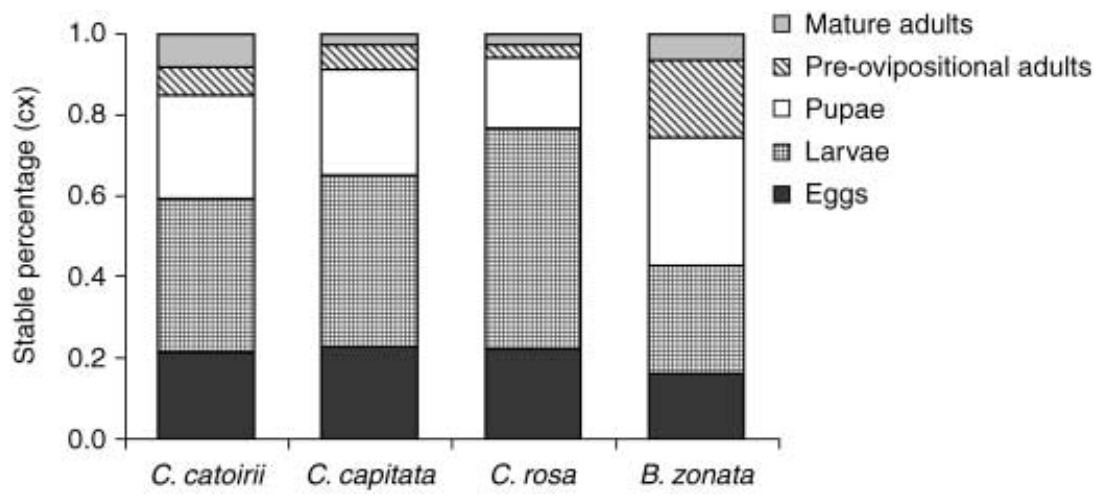

Table 2 Population parameters of Ceratitis catoirii, Ceratitis capitata, Ceratitis rosa, and Bactrocera zonata. 95\% confidence intervals were obtained by bootstrap (see Methods). ${ }^{\star}$ Means in the same line with the same superscript letter are not significantly different at the $5 \%$ level (Tukey HSD).

\begin{tabular}{|c|c|c|c|c|c|}
\hline Parameters & Units & $\begin{array}{l}\text { C. catoirii } \\
\text { value }[95 \% \mathrm{CI}]\end{array}$ & $\begin{array}{l}\text { C. capitata } \\
\text { value }[95 \% \mathrm{CI}]\end{array}$ & $\begin{array}{l}\text { C. rosa } \\
\text { value }[95 \% \mathrm{CI}]\end{array}$ & $\begin{array}{l}\text { B. zonata } \\
\text { value }[95 \% \mathrm{CI}]\end{array}$ \\
\hline Gross reproductive rate (GRR) & Eggs/female & $137.1[85.2,174.7]$ & $344.5[283.3,405.7]$ & $389.3[222.6,536.1]$ & $303.0[228.3,367.9]$ \\
\hline Net reproductive rate $\left(R_{0}\right)$ & Eggs/female & $18.2[10.6,25.8]$ & $130.6[87.5,162.5]$ & $128.4[76.1,177.7]$ & $66.3[33.7,101.2]$ \\
\hline Intrinsic rate of increase $(r)$ & & $0.059[0.048,0.066]$ & $0.115[0.104, \quad 0.123]$ & $0.110[0.097, \quad 0.119]$ & $0.069[0.057,0.077]$ \\
\hline Intrinsic birth rate $(b)$ & & $0.128[0.117,0.137]$ & $0.121[0.113,0.128]$ & $0.120[0.109, \quad 0.128]$ & $0.096[0.084,0.104]$ \\
\hline \multirow[t]{2}{*}{ Intrinsic death rate $(d)$} & & -0.069 & -0.006 & -0.010 & -0.027 \\
\hline & & {$[-0.071,-0.067]$} & {$[-0.009,-0.004]$} & {$[-0.012,-0.009]$} & {$[-0.030,-0.025]$} \\
\hline Mean generation time $(T)$ & Days & $48.8[46.3,51.5]$ & $42.3[39.9,44.9]$ & $44.2[41.8,47.3]$ & $60.6[57.7,64.8]$ \\
\hline $\begin{array}{l}\text { Average age in stable } \\
\text { population }(\bar{a})\end{array}$ & Days & $9.8[9.0,10.9]$ & $7.1[6.6,7.6]$ & $7.6[7.1,8.4]$ & $11.4[10.5,12.6]$ \\
\hline Mean egg size $\pm \mathrm{SD}^{*}$ & $\mathrm{~mm}$ & $1.026 \pm 0.032^{\mathrm{a}}$ & $0.783 \pm 0.025^{c}$ & $0.866 \pm 0.038^{\mathrm{b}}$ & $1.036 \pm 0.041^{\mathrm{a}}$ \\
\hline Pupal weight $\pm \mathrm{SD}^{*}$ & $10^{-4} \mathrm{~g}$ & $112 \pm 14^{\mathrm{b}}$ & $94 \pm 9^{\mathrm{d}}$ & $107 \pm 12^{c}$ & $118 \pm 13^{\mathrm{a}}$ \\
\hline
\end{tabular}

B. zonata, for which the senescence parameter is non-significant (Table 1). Similarly, the estimated doubling time of mortality was more than twice as long in B. zonata as in the other species.

Ceratitis capitata had the highest net reproductive rate followed by C. rosa, B. zonata, and C. catoirii, respectively (Table 2). Note that demographic parameters previously measured on C. capitata (Carey, 1982; Vargas et al., 2000) were similar to our estimates. In our data, the intrinsic rate of increase was similar for C. capitata and C. rosa, both of which were significantly higher than that of C. catoirii and B. zonata. The latter species has a significantly longer mean generation time than the other species: 60.6 days compared to $48.8,42.3$, and 44.2 for C. catoirii, C. capitata, and C. rosa, respectively. Immature stages represent the largest part of the theoretical stable age distributions in all species (Fig. 2). However, while the expected proportion of adults was $8 \%$ and $6 \%$, respectively, for C. capitata and C. rosa, it reached $15 \%$ in C. catoirii and $25 \%$ in B. zonata (mostly immature adults in the latter). Egg size (ANOVA $F_{3,196}=665.3, P<0.0001$ ) and pupal mass (ANOvA $F_{3,636}=40.3, P<0.0001$ ) were significantly different among the four species (Table 2). Egg size of B. zonata was similar to that of C. catoirii and significantly bigger than that of C. rosa, itself significantly bigger than that of C. capitata (Table 2; Fig. 3 ). Pupal mass followed the same pattern (except that pupae of $C$. catoirii were significantly lighter than those of B. zonata).

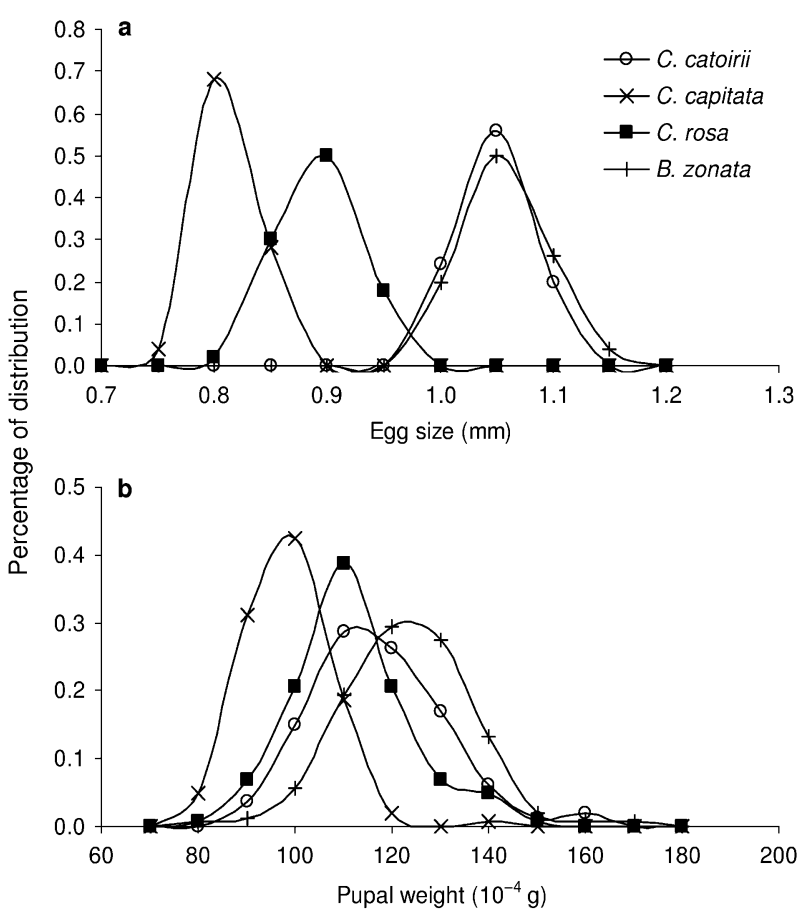

Figure 3 (a) Distributions of egg size (classes of $0.05 \mathrm{~mm}$ ) and (b) pupal weight (classes of $1 \mathrm{mg}$ ) of Ceratitis catoirii, C. capitata, C. rosa and Bactrocera zonata. 


\section{DISCUSSION}

\section{Life histories of tephritid species and trade-offs}

The life-history profiles of the three species B. zonata, C. capitata, and $C$. rosa seem consistent with the idea of a trade-off between traits favouring biomass accumulation and persistence and traits favouring the rapid production of many offspring. The major contrast lies between B. zonata and the Ceratitis spp., as the former has higher survival and longer duration of the reproductive period, while the other two have higher fecundity and earlier (but shorter) reproduction. Other trade-offs are apparent between the number of offspring on one hand, and both the investment per offspring (as measured by egg size) and the growth (reflected by pupal mass) on the other. These trade-offs are consistent not only with the comparison between Bactrocera and Ceratitis, but also, to a lesser extent, between C. capitata and C. rosa. Indeed, C. capitata has higher maximum fecundity and shorter pre-imaginal development, but smaller eggs and smaller pupae than C. rosa. The latter invests more in each offspring (larger egg size) and pre-imaginal growth, reaching larger pupal masses at the expense of a longer pre-imaginal development. As expected, the intrinsic rates of increase $(r)$ under optimal laboratory conditions are in the order B. zonata $<C$. rosa $<C$. capitata, the most pronounced contrast (and the only significant one, i.e. non-overlapping confidence intervals in Table 2) being between the first two. In consistency with the competitioncolonization and/or $r-K$ trade-off theory (Pianka, 1970; Tilman, 1994), this pattern is the opposite of the competitive hierarchy for these three species (B. zonata $>C$. rosa $>C$. capitata, in which, again, the largest contrast occurred between $B$. zonata and the other two; Duyck et al., 2006a).

In contrast, the combination of traits of $C$. catoirii, compared to the other three species, does not support the hypothesis of an interspecific trade-off. Basically C. catoirii does not counterbalance its low fecundity by a high survivorship. Although the decreased fecundity and large eggs of C. catoirii (as in B. zonata) are consistent with a trade-off between quantity and quality of offspring, this large investment per offspring does not seem to provide any advantage, as its mortality during the pre-adult stages is extremely high compared to the other three species. As a consequence, its intrinsic rate of increase under laboratory conditions $(r)$ is approximately half that of the other Ceratitis species. Competition experiments have shown that this species is also the poorest competitor of all four species studied (Duyck et al., 2006a). In short, this species is neither a good competitor nor a good colonist.

The differential age of the colonies of the different species may have affected the recorded life-history traits. However, genetic drift and inbreeding have been minimized in all colonies as they were maintained from the beginning using many individuals. Differential adaptation to laboratory conditions could also affect life-history traits. However, this hypothesis predicts that fitness traits would be higher in species cultured in the laboratory for more generations, which is not observed. For example, C. catoirii has distinctly lower values for many fitness traits although it is the oldest colony in our laboratory. Finally, another study on
C. capitata (Muniz, 1987) showed no significant differences in demographic parameters between an old laboratory colony (reared for 19 years) and a field population, suggesting limited effects of adaptation to laboratory conditions.

The imperfect trade-off observed in this study, even between phylogenetically closely related species, is not surprising since perfect trade-offs are the exception rather than the rule in the literature (Stearns, 1992; Reznick et al., 2002; Kneitel \& Chase, 2004). Two main causes are traditionally cited for imperfect trade-offs between two traits (Van Noordwijk \& Dejong, 1986; Stearns, 1992): first, species may differ by the total amount of resources they are able to extract from the environment rather than by relative allocation to different traits; second, energy may be diverted towards a third trait rather than shared among the two considered. Why the Mascarenes endemic C. catoirii does not follow the trade-off common to the three recent invaders remains hypothetical. Anthropogenic influences are relatively recent in La Réunion (four centuries), and populations of C. catoirii used to depend on resources from the natural forest habitat in pre-human times. It could invest in some form of specialization to this natural habitat that confers no benefit under 'optimal' laboratory conditions and secondary habitats. This is a mere hypothesis that remains to be tested. More generally, an important caveat for laboratory experiments is that life-history traits and competitive ranks may change depending on conditions, and that actual laboratory conditions may not be optimal for all species. In our case, however, laboratory diets have been optimized for each species, and larval development rates in these diets are better than in the best natural fruits tested to date (P. F. Duyck, unpublished data). Laboratory temperature $\left(25^{\circ} \mathrm{C}\right)$ is also optimal for all four species although C. rosa is clearly more cold-tolerant (see Duyck \& Quilici, 2002; Duyck et al., 2004b). We are therefore confident that our laboratory conditions are at least very favourable - if not truly optimal — for all species studied.

However, whatever the causes, C. catoirii is inferior to the other three species in terms of both colonizing and competitive ability. Ceratitis catoirii used to be abundant in cultivated habitats in La Réunion before the arrival of the other species (Orian \& Moutia, 1960). Following invasions of C. capitata, C. rosa, and B. zonata, C. catoirii has declined and is now very rare in La Réunion, and it has completely disappeared from Mauritius, where the same invasive tephritids have been introduced (Duyck et al., 2006a). All this strongly suggests a case of competitive exclusion.

\section{Competitive ability, traits, and invasion ranks}

Based on comparisons between life-history data (this study) and competition data (Duyck et al., 2006a), we can try to identify traits associated with competitive ability. Among the three exotic invasive species, size seems to be a major determinant of competition. Egg size influences larval competition: bigger eggs can reduce larval developmental times and thus confer a resource consumption advantage. This classical pre-emptive effect (Krijger et al., 2001) was observed in our previous work (Duyck et al., 2006a) in the form of relationships between pupal mass and developmental time, both at the interspecific and at the intraspecific 
levels: late-emerging pupae were smaller because faster-developing ones had already depleted the resource. Among the three invasive species, a larger adult size also seems to confer an advantage in females competing for ovipositional sites in the same fruit, as pupal size ranks correspond to dominance ranks in interspecific contests among such females (Duyck et al., 2006a). However, size is certainly not the only determinant of competition when considering the endemic species C. catoirii. This species lays large eggs, but is dominated by all others in larval competition, owing to a much higher larval mortality. Similarly, its large adult size is not associated to aggressive behaviour in interference contests, during which this species is systematically displaced by all others (Duyck et al., 2006a).

The common hypothesis that successful invaders are often $r$ strategists (Lodge, 1993; Rejmanek \& Richardson, 1996) depends on the assumption that competition is not a limiting factor for invasion. This is probably true in many - if not a majority — of cases, when invasions occur in disturbed habitats (Rejmanek, 1996; Lozon \& MacIsaac, 1997; Lonsdale, 1999) or habitats devoid of species phylogenetically and/or ecologically similar to the invader. However, with the worldwide increase in the frequency of invasions, the probability that related taxa be introduced successively in the same place increases (Mack et al., 2000; Mooney \& Cleland, 2001). In this case, invasion may ultimately depend on the ability to outcompete, or at least to resist competition exerted by, resident species. In line with this hypothesis, in our system, as a result of trade-offs, the intrinsic rate of increase $(r)$ decreases in successive invaders, while competition ability increases. In contradiction with this trend, the endemic $C$. catoirii, a species with very low $r$, was excluded by the three other species. This is not inconsistent with the hypothesis that invasions were competition-limited, as this species has the lowest competitive ability. However, it illustrates the fact that our hypothesis will only apply as far as trade-offs are respected, as the decrease in $r$ is entirely dependent on its negative correlation with competitive ability.

Could our hypothesis apply to other cases of invasion in the presence of related or similar resident species? In Hawaii, the introduced Bactrocera dorsalis (Hendel) largely displaced C. capitata, a previously established invader (Debach, 1966). Vargas et al. (2000) found that despite a relatively high fecundity, B. dorsalis shows a lower intrinsic rate of increase, a bigger size, a delayed onset of oviposition, and a longer life span compared to C. capitata. These authors conclude that $B$. dorsalis is less $r$-strategist than $C$. capitata, in agreement with our results. In general, the whole genus Bactrocera has a more K-orientated profile than Ceratitis, which would explain why the former has often displaced the latter during recent invasions, but not the reverse (Duyck et al., 2004a). Such situations are not restricted to tephritid flies however: studying inter-tidal snails, Byers (2000) suggested that competitive ability could be an important characteristic of biological invaders, as did Evans (2004) studying ladybirds, and Vila \& Weiner (2004) reached the same conclusion based on a review of competition experiments between resident and invasive plants. Facon et al. (2006) also predicted successive waves of invasions by ever-better competitors into the same niche.
Fruit flies in La Réunion are an example of a system in which life-history traits can confer competitive advantages for invading species, though we are not attempting to express a general paradigm applicable to any other system. Yet we believe that these observations should serve as a motivating example of how details of natural history can influence species invasiveness. Obviously, studying four species cannot provide evidence for a general negative relationship between $r$ and invasiveness. However, the limits of our data themselves suggest interesting ways of treating data sets so as to tackle the heterogeneity of invasion cases, frequently cited as the main cause of the scarcity of conclusive results in studies of relationships between traits and invasiveness (Holdgate, 1986; Lodge, 1993; Lonsdale, 1999; Kolar \& Lodge, 2001; Facon et al., 2004; Richardson \& Pysek, 2006). First, invasions in the absence of likely strong competitors, for example, a predator in an island devoid of predators (Fritts \& Rodda, 1998), or Spartina in bare mudflats (Davis, 2005), should be distinguished from invasions in the presence of competitors. A possible surrogate, in the absence of competition data, could be the absence or presence of related resident species with similar ecology. Rejmanek (1996) mentioned the fact that 'alien species belonging to exotic genera are more likely to be invasive than alien species from genera represented in the native flora'. This suggests that related residents pose a competitive limit to invasion, and that different mechanisms may underlie invasions in which exotics have to overcome this limit, and those in which they do no have to do so. An important caveat, however, is that the degree of phylogenetic conservation of niche traits seem rather variable among taxa (see the review of Webb et al., 2002) and that other conserved aspects (for example, parasite or enemy assemblages) may be more important than resource overlap and competition in shaping interactions between newly co-occurring congeneric species.

Second, in the case of invasion in the presence of resident competitors, both invasiveness and traits should be considered relative to residents rather than in absolute terms (see Daehler, 2003). For example, C. capitata was once invasive in the presence of $C$. catoirii alone, but is no longer invasive in La Réunion since the better competitors B. zonata and C. rosa arrived. Similarly, in our case, the trait values of the invader are less relevant than the differences between invader and previously established species (e.g. larger pupae or larger eggs relative to residents provide higher competitive ability and trigger invasion).

The last suggestion from our work is to distinguish direct predictions (e.g. $r$-traits are favourable to colonization in noncompetitive contexts) from predictions mediated by a trade-off ( $r$-traits should be negatively correlated with invasion in competitive contexts); the latter, not the former, will depend on how well the assumed trade-off applies to the set of taxa studied, which can be measured directly, as in our Tephritid example.

In conclusion, neither $r$ nor $K$ strategies are likely to be important for invasions in general. In some groups, such as conifers (Rejmanek \& Richardson, 1996), invaders have more $r$-orientated traits than non-invaders. It would be interesting to see whether the majority of conifer invasions happened in the absence of related species and/or in relatively non-competitive habitats, as suggested by the fact that many Pinus invasive species are 
opportunistic and abundant in disturbed habitats rather than in mature forest (Grotkopp et al., 2002). In addition, for invasions that happen in the presence of competitors, invaders may be at the same time better competitors (and worse colonists) than resident species, and better colonists than other potential invaders. Among those candidate invasive species that can overcome competition with residents, the first to invade may indeed be the better colonists. If our conclusions are confirmed by further studies, this framework could provide an important tool in Pest Risk Analysis for the prediction of potential invaders as a function of established regional communities, in addition to the use of measures of environmental suitability of regions to target species (e.g. climatic matching).

\section{ACKNOWLEDGEMENTS}

We thank Serge Glénac and Jim Payet for maintaining tephritid cultures, Raquel Ceniceros for technical assistance, Gérard Duvallet and John Thompson for discussions on relationships between interspecific competition and invasions, and Doyle McKey for reviewing an earlier version of the manuscript. We are also grateful to three anonymous reviewers for their suggestions. This work was funded by CIRAD, by the 'Conseil Régional de La Réunion', and the European Agricultural Guidance and Guarantee Fund (EAGGF).

\section{REFERENCES}

Bishop, M.J. \& Peterson, C.H. (2006) When r-selection may not predict introduced-species proliferation: Predation of a nonnative oyster. Ecological Applications, 16, 718-730.

Bruno, J.F., Kennedy, C.W., Rand, T.A. \& Grant, M.B. (2004) Landscape-scale patterns of biological invasions in shoreline plant communities. Oikos, 107, 531-540.

Byers, J.E. (2000) Competition between two estuarine snails: implications for invasions of exotic species. Ecology, 81, 1225-1239.

Byers, J.E. (2002) Impact of non-indigenous species on natives enhanced by anthropogenic alteration of selection regimes. Oikos, 97, 449-458.

Carey, J.R. (1982) Demography and population dynamics of the Mediterranean fruit fly. Ecological Modelling, 16, 125-150.

Carey, J.R. (2001) Insect biodemography. Annual Review of Entomology, 46, 79-110.

Caswell, H. (2001) Matrix population models: construction, analysis and interpretation, 2nd edn. Sinauer Associates Inc, Sunderland, Massachusetts.

Charlesworth, B. (1994) Evolution in age-structured populations. University of Chicago Press, Chicago.

Crawley, M.J. (1986) The population biology of invaders. Philosophical Transactions of the Royal Society of London Series B, Biological Sciences, 711-731.

Crawley, M.J. (1993) GLIM for ecologist. Blackwell, Oxford.

Daehler, C.C. (2003) Performance comparisons of co-occurring native and alien invasive plants: Implications for conservation and restoration. Annual Review of Ecology, Evolution and Systematics, 34, 183-211.
Davis, H.G. (2005) r-selected traits in an invasive population. Evolutionary Ecology, 19, 255-274.

Debach, P. (1966) Competitive displacement and coexistence principles. Annual Review of Entomology, 11, 183-212.

Duyck, P.F., David, P., Junod, G., Brunel, C., Dupont, R. \& Quilici, S. (2006a) Importance of competition mechanisms in successive invasions by polyphagous tephritids in La Réunion. Ecology, 87, 1170-1180.

Duyck, P.F., David, P. \& Quilici, S. (2004a) A review of relationships between interspecific competition and invasions in fruit flies (Diptera: Tephritidae). Ecological Entomology, 29, 511-520.

Duyck, P.F., David, P. \& Quilici, S. (2006b) Climatic niche partitioning following successive invasions by fruit flies in La Réunion. Journal of Animal Ecology, 75, 518-526.

Duyck, P.F. \& Quilici, S. (2002) Survival and development of different life stages of three Ceratitis spp. (Diptera: Tephritidae) reared at five constant temperatures. Bulletin of Entomological Research, 92, 461-469.

Duyck, P.F., Sterlin, J.F. \& Quilici, S. (2004b) Survival and development of different life stages of Bactrocera zonata (Diptera: Tephritidae) reared at five constant temperatures compared to other fruit fly species. Bulletin of Entomological Research, 94, 89-93.

Ebert, T. (1999) Plant and animal populations - Methods in demography. Harcourt Brace \& Company, San Diego.

Efron, B. \& Tibshirani, R.J. (1993) An introduction to the bootstrap. Chapman \& Hall, London.

Elton, C.S. (1958) The ecology of invasions by animals and plants. Methuen, London.

Evans, E.W. (2004) Habitat displacement of North American ladybirds by an introduced species. Ecology, 85, 637-647.

Facon, B., Genton, B.J., Shykoff, J., Jarne, P., Estoup, A. \& David, P. (2006) A general eco-evolutionary framework for understanding bioinvasions. Trends in Ecology \& Evolution, 21, 130-135.

Facon, B., Machline, E., Pointier, J.P. \& David, P. (2004) Variation in desiccation tolerance in freshwater snails and its consequences for invasion ability. Biological Invasions, 6, 283-293.

France, K.E. \& Duffy, J.E. (2006) Consumer diversity mediates invasion dynamics at multiple trophic levels. Oikos, 113, 515-529.

Fritts, T.H. \& Rodda, G.H. (1998) The role of introduced species in the degradation of island ecosystems: a case history of Guam. Annual Review of Ecology and Systematics, 29, 113-140.

Gray, A.J. (1986) Do Invading species have definable genetic characteristics? Philosophical Transactions of the Royal Society of London Series B, Biological Sciences, 314, 655-674.

Grime, J.P. (1977) Evidence for the existence of three primary strategies in plants and its relevance to ecological and evolutionary theory. The American Naturalist, 111, 1169-1194.

Grotkopp, E., Rejmanek, M. \& Rost, T.L. (2002) Toward a causal explanation of plant invasiveness: Seedling growth and lifehistory strategies of 29 pine (Pinus) species. The American Naturalist, 159, 396-419.

Holdgate, M.W. (1986) Summary and conclusions: characteristics and consequences of biological invasions. Philosophical Transactions of the Royal Society of London Series B, Biological Sciences, 314, 733-742.

Kneitel, J.M. \& Chase, J.M. (2004) Trade-offs in community 
ecology: linking spatial scales and species coexistence. Ecology Letters, 7, 69-80.

Kolar, C.S. \& Lodge, D.M. (2001) Progress in invasion biology: predicting invaders. Trends in Ecology \& Evolution, 16, 199-204.

Krijger, C.L., Peters, Y.C. \& Sevenster, J.G. (2001) Competitive ability of Neotropical Drosophila predicted from larval development times. Oikos, 92, 325-332.

Levine, J.M. (2000) Species diversity and biological invasions: Relating local process to community pattern. Science, 288, 852-854.

Lodge, D.M. (1993) Biological invasions - Lessons for ecology. Trends in Ecology \& Evolution, 8, 133-137.

Lonsdale, W.M. (1999) Global patterns of plant invasions and the concept of invasibility. Ecology, 80, 1522-1536.

Lozon, J.D. \& MacIsaac, H.J. (1997) Biological invasions: are they dependent on disturbance? Environmental Reviews, 5, 131-144.

MacArthur, R.H. (1962) Some generalized theorems of natural selection. Proceedings of the National Academy of Sciences USA, 48, 1893-1897.

Mack, R.N. (1996) Predicting the identity and fate of plant invaders: emergent and emerging approaches. Biological Conservation, 78, 107-121.

Mack, R.N., Simberloff, D., Lonsdale, W.M., Evans, H., Clout, M. \& Bazzaz, F.A. (2000) Biotic invasions: causes, epidemiology, global consequences, and control. Ecological Applications, 10, 689-710.

Mooney, H.A. \& Cleland, E.E. (2001) The evolutionary impact of invasive species. Proceedings of the National Academy of Sciences USA, 98, 5446-5451.

Mueller, L.D. (1997) Theoretical and empirical examination of density-dependent selection. Annual Review of Ecology and Systematics, 28, 269-288.

Muniz, M. (1987) Larval development and reproductive characters of field and laboratory populations of the Mediterranean fruit fly Ceratitis capitata Wied. Bolletino Di Zoologia Agraria E Di Bachicoltura, Series II, 19, 111-118.

Orian, A.J.E. \& Moutia, L.A. (1960) Fruit flies (Trypetidae) of economic importance in Mauritius. Revue Agricole et Sucrière de l'Ile Maurice, 39, 142-150.

Pianka, E.R. (1970) On r- and k-selection. The American Naturalist, 104, 592-597.

Radford, I.J. \& Cousens, R.D. (2000) Invasiveness and comparative life-history traits of exotic and indigenous Senecio species in Australia. Oecologia, 125, 531-542.

Rejmanek, M. (1996) A theory of seed plant invasiveness: the first sketch. Biological Conservation, 78, 171-181.

Rejmanek, M. \& Richardson, D.M. (1996) What attributes make some plant species more invasive? Ecology, 77, 1655-1661.
Reznick, D., Bryant, M.J. \& Bashey, F. (2002) $r$ - and $K$-selection revisited: The role of population regulation in life-history evolution. Ecology, 83, 1509-1520.

Richardson, D.M. \& Pysek, P. (2006) Plant invasions: merging the concepts of species invasiveness and community invasibility. Progress in Physical Geography, 30, 409-431.

Richardson, D.M. \& Rejmanek, M. (2004) Conifers as invasive aliens: a global survey and predictive framework. Diversity and Distributions, 10, 321-331.

Shea, K. \& Chesson, P. (2002) Community ecology theory as a framework for biological invasions. Trends in Ecology \& Evolution, 17, 170-176.

Stachowicz, J.J., Fried, H., Osman, R.W. \& Whitlatch, R.B. (2002) Biodiversity, invasion resistance, and marine ecosystem function: Reconciling pattern and process. Ecology, 83, 2575-2590.

Stachowicz, J.J. \& Tilman, D. (2005) Species invasions and the relationships between species diversity, community saturation and ecosystem functioning. Species invasions: insight into ecology, evolution and biogeography (ed. by D.F. Sax, J.J. Stachowicz and S.D. Gaines), pp. 41-64. Sinauer Associates Inc, Sunderland, Massachusetts.

Stearns, S.C. (1992) The evolution of life-histories. Oxford University Press, Oxford.

Thuiller, W., Richardson, D.M., Rouget, M., Proches, S. \& Wilson, J.R.U. (2006) Interactions between environment, species traits, and human uses describe patterns of plant invasions. Ecology, 87, 1755-1769.

Tilman, D. (1994) Competition and biodiversity in spatially structured habitats. Ecology, 75, 2-16.

Van Noordwijk, A.J. \& Dejong, G. (1986) Acquisition and allocation of resources - Their influence on variation in life-history tactics. The American Naturalist, 128, 137-142.

Vargas, R.I., Walsh, W.A., Kanehisa, D., Stark, J.D. \& Nishida, T. (2000) Comparative demography of three Hawaiian fruit flies (Diptera: Tephritidae) at alternating temperatures. Annals of the Entomological Society of America, 93, 75-81.

Vila, M. \& Weiner, J. (2004) Are invasive plant species better competitors than native plant species? Evidence from pair-wise experiments. Oikos, 105, 229-238.

Vitousek, P.M., D’Antonio, C.M., Loope, L.L. \& Westbrooks, R. (1996) Biological invasions as global environmental change. American Scientist, 84, 468-478.

Webb, C.O., Ackerly, D.D., McPeek, M.A. \& Donoghue, M.J. (2002) Phylogenies and community ecology. Annual Review of Ecology and Systematics, 33, 475-505.

Williamson, M. (1996) Biological Invasions. Chapman \& Hall, London. 